\title{
Analisis Angka Reproduksi Dasar Model Matematika Penyebaran HIV Melalui Jarum Suntik pada Populasi Pengguna Narkoba
}

\author{
Anita Triska, Nurul Gusriani \\ Departemen Matematika Fakultas MIPA, Universitas Padjadjaran \\ Jl. Raya Bandung Sumedang KM 21 Jatinangor Sumedang 45363 \\ Email: anit.triska@gmail.com
}

\begin{abstract}
ABSTRAK
Penyebaran HIV memiliki kompleksitasnya sendiri, diantarannya masa inkubasi yang lama. Penelitian-penelitian sebelumnya laju penginfeksian diasumsikan konstan, sedangkan laju penginfeksian akan berbeda sesuai dengan strutur populasinya, seperti pada populasi homoseksual, heteroseksual, pengguna narkoba atau populasi dengan kombinasi aktivitas beresiko. Makalah ini membahas tentang model penyebaran HIV melalui jarum suntik pada pengguna narkoba. Fokus utama pada studi ini adalah menentukan laju penginfeksian (force of infection) penyebaran HIV melalui jarum suntik yang tidak konstan pada populasi pengguna narkoba sehingga diperoleh model yang lebih realistis. Dilanjutkan dengan menentukan angka reproduksi dasar sebagai ambang batas terjadinya suatu wabah penyakit. Angka reproduksi dasar tersebut kemudian disimulasikan untuk mendapatkan parameter yang dapat dikontrol agar dapat menekan angka reproduksi dasar tetap berada dibawah ambang batas. Penelitian dilakukan melalui model SIR yang dimodifikasi menjadi model SIA dan analisis matematika sebagai salah satu langkah untuk memahami sebuah fenomena alam. Laju penginfeksian dan angka reproduksi dasar yang diperoleh membawa pada kesimpulan bahwa agar angka reproduksi dasar tetap berada pada ambang batasnya maka populasi pengguna narkoba dibagi pada grup-grup yang cukup banyak.
\end{abstract}

Kata kunci: model matematika HIV, laju penginfeksian, angka reproduksi dasar

\section{ABSTRACT}

The spread of HIV has its complexity, such a long incubation period. Previous studies assumed force of infection as a constant, whereas it will be different according to the structure of the population, like in population of homosexual, heterosexual, drug user or population with combination of risk activities. This paper discusses the model of the spread of HIV through needle on drug users population. The main focus of this study is to determine force of infection of the spread of HIV through needle which is not constant in a population of drug users, so thatwe obtain more realistic model. Next we determine the basic reproduction number as the threshold of occurrence of an outbreak of the disease. The basic reproduction number is simulated to obtain the parameters that can be controlled in order to make the basic reproduction number remained below its threshold. This research use modification of SIR model become SIA model and mathematical analysis as one of the steps to understand a phenomenon of nature. The force of infection and basic reproduction number led to the conclusion that in order to make it remain below the threshold, then population of drug users must be divided into many groups.

Keywords: HIV transmission model, force of infection, basic reproduction number

\section{Pendahuluan}

Salah satu aktivitas yang berisiko menularkan HIV adalah mengonsumsi narkoba dengan alat suntik secara bergantian dalam sebuah grup. Menurut data World Health Organization (WHO) penyebab utama dari penyebaran HIV/AIDS di banyak negara adalah melalui hubungan seks dan penggunakan alat suntik bersama-sama sewaktu mengkonsumsi narkoba [2]. Di Indonesia sendiri, sampai Februari 2013 sekitar 40\% dari kasus yang ada disebabkan oleh perilaku penggunaan alat suntik yang terinfeksi HIV pada populasi pengguna narkoba. Penyebab ini berada pada posisi kedua setelah hubungan seks yang mencapai 53\% [8]. Melihat penyebaran melalui jarum suntik pada pengguna narkoba cukup banyak maka dirasa sangat penting untuk mengkaji lebih lanjut dinamika penyebaran HIV pada populasi ini. 
Model matematika adalah salah satu cara yang dapat dilakukan untuk membantu memahami sebuah fenomena alam melalui abstraksi masalah [3,4]. Model dapat memprediksi keadaan di masa depan dan mengindikasikan apakah kasus HIV akan mewabah sehingga terjadi epidemik atau tidak. Melalui model juga dapat diketahui faktor-faktor yang berperan penting dalam penyebarannya sehingga dapat ditentukan langkah strategis yang harus dilakukan untuk pencegahannya.

Sebelumnya telah banyak literatur yang membahas tentang model matematika untuk penyebaran HIV/AIDS pada pecandu narkoba [1, 5, 6, 7, 8]. Namun demikian penelitian tersebut masih menyatakan laju penginfeksian sebagai sebuah nilai yang sama untuk struktur populasi yang berbeda. Sedangkan laju penginfeksian akan berbeda sesuai dengan struktur populasinya, seperti pada populasi yang homoseksual, heteroseksual, pengguna narkoba dan lainnya.

Misalnya, seorang individu akan lebih mudah terinfeksi jika melakukan hubungan seks dengan lebih dari satu orang pasangan dan akan lebih rentan jika pasangannnya berasal dari kelompok yang beresiko tinggi terinfeksi HIV atau pada kondisi dimana seorang individu sering mengkonsumsi narkoba dengan alat suntik yang bergantian. Secara intuisi seorang yang sering melakukan hubungan seks dengan pasangan yang berbeda-beda sekaligus seorang pengguna narkoba jauh lebih beresiko. Individu yang tinggal di sebuah kota besar yang padat penduduk dengan kebiasaan hidup bebas akan memberikan tingkat resiko yang berbeda dengan individu yang berdomisili di kota kecil. Sangat terlihat bahwa perilaku berbeda yang beresiko terinfeksi dalam sebuah populasi memberikan laju penginfeksian yang berbeda pula. Untuk itu sangat penting menyatakan sebuah laju penginfeksian sebagai sebuah fungsi yang menyatakan tingkat yang berbeda pada setiap struktur populasi yang tidak sama.

Penelitian ini menyatakan laju penginfeksian sebagai sebuah fungsi pada populasi pengguna narkoba dan menentukan angka reproduksi dasar sehingga akan terlihat secara eksplisit parameter apa saja yang memengaruhi penyebaran HIV pada populasi pengguna narkoba. Analisis terhadap angka reproduksi dasar juga dilakukan utuk melihat parameter yang mungkin dikontrol sehingga dapat dijadikan sebagai salah satu langkah strategis pencegahan penyebaran HIV khususnya pada populasi pengguna narkoba.

\section{Metode Penelitian}

Penelitian ini dilakukan dengan metode studi literarur melalui pendekatan model matematika SIR (Susceptible, Infected, Recovery) dan analisis matematika. Model SIR kemudian dimodifikasi menjadi SIA (Susceptible, Infected, AIDS) karena sampai saat ini belum ada individu dengan HIV dinyatakan sembuh. Model matematika merupakan suatu representasi yang berbentuk teori dan konsep matematika dari sebuah fenomena yang menjadi objek kajian serta sebagai salah satu langkah yang digunakan untuk memahami sebuah fenomena alam dengan mengabstraksinya kepada sebuah model matematika.

\section{Hasil dan Pembahasan}

\subsection{Model Penyebaran HIV pada Populasi Pengguna Narkoba}

Penyebaran HIV dari pada populasi pengguna narkoba dari individu yang sehat (Susceptible), terinfeksi (Infected), dan positif AIDS (AIDS) digambarkan oleh diagram aliran pada Gambar 1 berikut. Diagram tersebut merupakan modifikasi dari model aliran SIR (Susceptible-Infected-Recovery) menjadi SIA (Susceptible, Infected, AIDS) dengan menyatakan laju penginfeksian sebagai sebuah fungsi dipengaruhi oleh interaksi pengguna yang sehat dan yang terinfeksi [6]. 


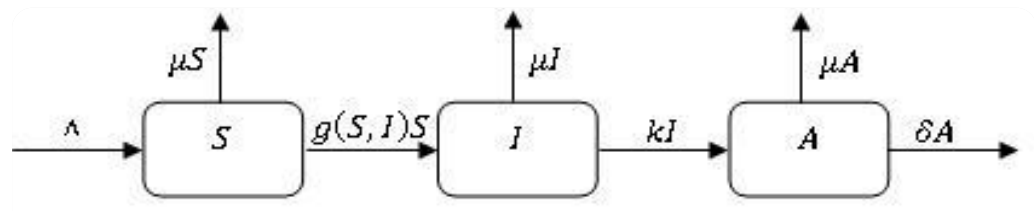

Gambar 1. Aliran Perpindahan Individu pada Populasi Pengguna Narkoba

dengan

$S \quad$ Jumlah pengguna yang susceptible (orang)

I Jumlah pengguna yang terinfeksi HIV (orang)

A Jumlah pengguna yang positif AIDS (orang)

$\Lambda \quad$ Laju pertambahan pengguna susceptible baru dalam suatu grup (orang/satuan waktu)

$\mu \quad$ Laju kematian alami (orang/satuan waktu)

$g(S, I)$ Laju penginfeksian pengguna terinfeksi terhadap susceptible

(force of infection) (orang/satuan waktu)

$\mathrm{k} \quad$ Laju perpindahan seorang pengguna dari HIV menjadi AIDS (orang/satuan waktu)

$\delta \quad$ Laju kematian akibat AIDS (orang/satuan waktu)

Dari diagram tersebut diperoleh model penyebaran HIV

$$
\begin{aligned}
& \frac{d S}{d t}=\Lambda-\mu S-g(S, I) S \\
& \frac{d I}{d t}=g(S, I) S-\mu I-\kappa I \\
& \frac{d A}{d t}=\kappa I-\mu A-\delta A
\end{aligned}
$$

\subsection{Laju Penginfeksian}

Laju penginfeksian adalah peluang individu yang sehat namun rentan terhadap penyakit (susceptible) menjadi terinfeksi suatu penyakit menular per satuan waktu [9]. Laju penginfeksian dalam kasus ini diperoleh dengan cara merunut perjalanan seorang pengguna narkoba yang sebelumnya tidak terinfeksi menjadi terinfeksi dengan mempertimbangkan halhal utama penyebab penularannya. Asumsikan bahwa satu-satunya cara pengguna narkoba terinfeksi adalah hanya dengan menggunakan alat suntik terinfeksi tanpa melihat aktivitas lain di luar grup. Oleh karena itu laju penginfeksian dipengaruhi oleh ukuran grup, apakah seorang pengguna mendapatkan alat suntik yang terinfeksi dan peluang terinfeksi jika mendapatkan alat suntik terinfeksi.

Asumsi berikutnya adalah bahwa dalam grup pengguna narkoba, ada seorang individu yang telah terinfeksi HIV. Langkah utama yang harus dilakukan adalah menentukan peluang seseorang pengguna pada sebuah grup mendapatkan alat suntik yang terinfeksi (terpapar). Hanya ada dua cara, yaitu jika penguna sebelumnya adalah seorang yang terinfeksi HIV atau tidak terinfeksi namun tidak membilas jarum suntik terinfeksi dengan darahnya pada saat gilirannya. Laju seorang pengguna yang susceptible terinfeksi (force of infection) dinotasikan dengan $g(S, I)$ dipengaruhi oleh tiga faktor, yaitu $\lambda, \alpha$, dan $\beta(S, I)$ sehingga $g(S, I)$ dapat ditulis sebagai berikut

$$
g(S, I)=\lambda \alpha \beta(S, I)
$$

dengan $\lambda$ adalah banyak pengguna yang datang pada sebuah grup, $a$ adalah peluang seorang pengguna yang terpapar menjadi terinfeksi, dan $\beta(S, I)$ adalah peluang seorang pengguna terpapar. Laju penginfeksian sangat dipengaruhi oleh $\beta(S, I)$. Semakin besar peluang seorang pengguna terpapar, maka semakin besar peluang seorang pengguna terinfeksi.

Untuk itu terlebih dahulu ditentukan peluang seorang pengguna susceptible terpapar, yaitu peluang seorang susceptible pada saat gilirannya mendapatkan dan menggunakan alat suntik yang tercemar. Dari ketiga faktor diatas, $\beta(S, I)$ sangat berperan dalam menentukan $g(S, I)$. Jika $\beta(S, I)$ dapat dinyatakan secara eksplisit maka $g(S, I)$ dapat dinyatakan secara eksplisit pula. Misalkan $E$ adalah kejadian seorang pengguna mendapatkan alat suntik yang 
tercemar HIV dan $G$ adalah ukuran grup secara acak. Peluang seorang pengguna susceptible terpapar juga dipengaruhi oleh banyaknya jumlah pengguna yang berpartisipasi dalam grup tersebut (ukuran grup) dan $G$ merupakan variabel acak, maka peluangnya pun dapat diukur dan diperhitungkan. Misalkan $G$ berukuran $k ; k=2 ; 3, \ldots$ maka $\beta(S, I)$ diperoleh:

$$
\begin{aligned}
\beta(S, I) & =P(E) \\
& =\sum_{k=2}^{\infty} P(E \mid G=k) P(G=k) \\
& =P(E \mid G=2) P(G=2)+P(E \mid G=3) P(G=3)+\ldots \\
& =\frac{P(E, G=2)}{P(G=2)} P(G=2)+\frac{P(E, G=3)}{P(G=3)} P(G=3)+\ldots \\
& =P(E, G=2)+P(E, G=3)+\ldots \\
& =P(E) P(G=2)+P(E) P(G=3)+\ldots \\
& =[P(G=2)+P(G=3)+\ldots] P(E) \\
& =\left[\sum_{k=2}^{\infty} P(G=k)\right] P(E)
\end{aligned}
$$

Persamaan (3) menyatakan bahwa ukuran grup mempengaruhi peluang terpaparnya seorang susceptible. Namun besarnya ukuran grup juga mempengaruhi urutan pemakaian alat suntik. Semakin banyak pengguna dalam grup tersebut maka semakin lama seorang pengguna mendapat giliran yang berdampak terhadap sterilisasi alat suntik yang digunakan. Semakin lama seorang pengguna susceptible mendapatkan alat suntik semakin besar peluangnya mendapatkan alat suntik yang tercemar sehingga dalam menentukan $\beta(S ; I)$ urutan pemakaian alat suntik perlu diperhitungkan. Misalkan dalam sebuah grup $G, R(k)$ menyatakan urutan pemakaian alat suntik dalam sebuah grup yang beranggotakan sebanyak $k$ orang, maka $P(E)$ pada persamaan (3) dapat ditulis sebagai

$$
\begin{aligned}
\beta(S, I) & =\left[\sum_{k=2}^{\infty} P(G=k)\right] P(E) \\
& =\sum_{k=2}^{\infty} P(G=k) \sum_{j=1}^{k} P(E \mid G=k, R(k)=j) P(R(k)=j)
\end{aligned}
$$

Persamaan (4) menyatakan peluang seorang pengguna terpapar HIV dalam sebuah grup pengguna narkoba yang berukuran $k$, dengan pemakaian alat suntik pada urutan ke $j$.

Berikut akan ditentukan nilai masing-masing komponen pembentuk $\beta(S ; I)$. Peluang seorang mendapatkan urutan ke $j$ dalam sebuah grup dengan ukuran $k$ adalah sama sehingga $P(R(k)=j)=1 / k$. Peluang seorang pengguna mendapatkan alat suntik yang terinfeksi pada urutan ke $j$ dalam sebuah grup yang terdiri dari $k$ orang, $P(E \mid G=k, R(k)=j)$, diilustrasikan sebagai berikut

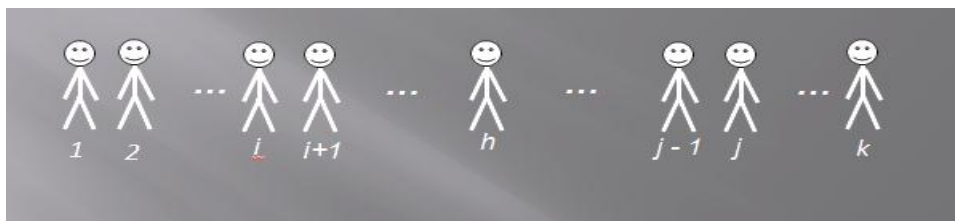

Gambar 2. Urutan Perjalanan Alat Suntik Hingga pada urutan ke $j$

Diasumsikan satu - satunya cara seorang pengguna terinfeksi adalah melalui alat suntik yang tercemar sehingga seorang pengguna ke $j$ akan berpeluang terinfeksi jika menggunakan alat suntik yang tercemar. Sedangkan tercemar atau tidaknya sebuah alat suntik ditentukan oleh pemakai sebelumnya, yaitu mulai dari pemakai pertama sampai ke pemakai $j-1$.

Misalkan pemakai ke $i$ adalah pengguna pertama yang terinfeksi HIV yang memakai alat suntik, $1 \leq i \leq j-1$. Ketika alat suntik berpindah dari pemakai ke $i$ sampai $j-1$ kemungkinan ada pengguna yang tidak terinfeksi. Alat suntik akan tercemar jika digunakan oleh pengguna yang terinfeksi, yaitu pengguna ke $i$, maka pengguna $i+1$, yaitu pengguna yang tidak terinfeksi, akan melakukan proses "pembilasan" jarum suntik dengan peluang sebesar $\theta$. Jika terjadi proses pembilasan, akibatnya pengguna berikut tidak terinfeksi. Proses 
ini berlangsung sampai pengguna ke $j-1$ : Misalkan $h$ adalah pengguna yang tidak terinfeksi dan tidak membersihkan alat suntik, dimana $h=i+1, \ldots, j-1$, diperoleh

$$
P(E \mid G=k, R(k)=j)=P(I i) \cdot P(U i)
$$

dengan $I i$ kejadian dimana pengguna ke $i$ terinfeksi dan $U i$ kejadian pengguna ke $h$ yang tidak terinfeksi dan tidak membilas alat suntik. Jika peluang seorang pecandu terinfeksi,

$$
P(I i)=I /(I+S)=\pi \quad \text { dan } \quad P(U i)=(1-\pi)^{j-1-i}(1-\theta)^{j-1-i} \quad \text { maka diperoleh }
$$

$$
P(E \mid G=k, R(k)=j)=P(I i) \cdot P(U i)=\sum_{i=1}^{j-1} \pi\left((1-\pi)^{j-1-i}(1-\theta)^{j-1-i}\right)
$$

Dengan demikian didapat peluang seorang pengguna terpapar sebagai berikut

atau

$$
\begin{aligned}
& \beta(S, I)=\frac{I}{\theta S+I}\left(1-\frac{(v-1)(S+I)+[(1-v(1-\theta)) S+I] e^{-v(\theta S+I) /(S+I)}}{v^{2}[\theta S+I]}\right) \\
& \beta(S, I)=\frac{\pi}{1-(1-\pi)(1-\theta)}\left(1-\frac{v-1+\left[1-v(1-\theta)(1-\pi) e^{-v[1-(1-\pi)(1-\theta)]}\right.}{v^{2}[1-(1-\pi)(1-\theta)]}\right)
\end{aligned}
$$

Peluang seorang pengguna terpapar $\beta(S, I)$, sangat dipengaruhi oleh dua parameter, yaitu peluang seorang pengguna susceptible "membilas" alat suntik yang tercemar HIV $(\theta)$, dan rata-rata banyaknya grup yang terbentuk, $v$.

\subsection{Angka Reproduksi Dasar (Ro)}

Angka reproduksi dasar adalah rata-rata banyaknya kasus sekunder yang ditimbulkan oleh kasus primer dalam suatu populasi yang virgin. Secara sederhana dapat diartikan sebagai rata-rata banyaknya kasus sekunder yang ditimbulkan oleh seseorang yang terinfeksi ketika individu tersebut masuk ke dalam suatu populasi yang rentan terinfeksi. Angka reproduksi dasar (Ro) berikut diperoleh dengan menggunakan metode Next Generation Matrix berdasarkan kasus yang dibahas, yaitu:

$$
R_{0}=\frac{\lambda \alpha}{(\mu+\kappa)}\left(1-\frac{v-1+[1-v(1-\theta)] e^{-v \theta}}{v^{2} \theta}\right)
$$

Angka reproduksi dasar adalah suatu ambang dalam penyebaran suatu penyakit menular. Jika $R o<1$ maka HIV tidak akan mewabah secara luas bahkan akan menghilang dengan sendirinya. sedangkan jika saat $R_{o}>1$ maka jumlah individu terinfeksi HIV akan terus bertambah hingga mencapai titik ekuilibriumnya.

Dari model yang dibahas didapat titik-titik ekuilibrium, yaitu titik ekuilibrium bebas penyakit dan tidak bebas penyakit (saat terjadi wabah penyakit).

Jika $R_{0}<1$ maka

- Titik ekulibrium hanya ada satu yaitu titik non-endemik (bebas penyakit)

- Titik non-endemik tersebut adalah $E_{0}=\left(\frac{\Lambda}{\mu}, 0\right)$. Komponen awal menunjukkan jumlah individu yang sehat sedangkan komponen berikut menyatakan jumlah individu yang terinfeksi. Terlihat pada titik ini jumlah individu yang terinfeksi tidak ada.

- Titik ekuilibrium non-endemik tersebut ini bersifat stabil global asimtotik, artinya untuk setiap jumlah individu yang terinfeksi pada awal waktu namun seiring waktu akan hilang dengan sendirinya

Jika $R_{0}>1$ maka

- Ada dua titik ekuilibrium, yaitu titik non-endemik dan titik endemik

- Titik non-endemik tersebut adalah $E_{0}=\left(\frac{\Lambda}{\mu}, 0\right)$. Komponen awal menunjukkan jumlah individu yang sehat sedangkan komponen berikut menyatakan jumlah individu yang terinfeksi.

- Titik endemik tersebut adalah $E_{1}=\left(\frac{\Lambda}{\mu+\kappa}, \frac{\Lambda}{\mu}\right)$. Komponen awal menunjukkan jumlah individu yang sehat sedangkan komponen berikut menyatakan jumlah individu yang terinfeksi. Titik ekuilibrium non-endemik ini tidak stabil sedangkan titik endemik bersifat stabil lokal asimtotik, artinya jika $R o>1$ maka dipastikan penyakit akan terus meluas dan mewabah di masyarakat. 


\subsection{Analisis Angka Reproduksi Dasar (Ro)}

Upaya mencegah terus bertambahnya jumlah individu yang terinfeksi HIV pada populasi pengguna narkoba, diperlukan dukungan semua pihak terlebih dengan belum ditemukannya obat maupun vaksin yang mematikan HIV. Mencegah menularnya HIV merupakan langkah tepat untuk menghindari bertambahnya jumlah individu terinfeksi.

HIV tidak akan mewabah jika angka reproduksi dasarnya tidak melewati ambang batasnya. Hal ini bisa dijadikan sebagai langkah awal untuk melihat apa yang bisa dilakukan untuk mencegah HIV berpindah dari satu individu ke individu lain. Angka reproduksi dasar yang telah diperoleh sebelumnya memuat enam parameter, yaitu:

1. $\lambda$ yaitu rata-rata banyaknya kedatangan pengguna ke sebuah grup

2. $\alpha$ yaitu peluang seorang pengguna susceptible terpapar terinfeksi

3. $\mu$ yaitu laju kematian alami

4. $\kappa$ yaitu laju perpindahan pengguna yang positf HIV menjadi AIDS

5. $\theta$ yaitu peluang seorang susceptible "membilas" alat suntik

6. $v$ yaitu rata-rata banyaknya gup yang terbentuk

Diantara enam parameter tersebut tidak semua yang dapat dikontrol agar menekan angka reproduksi dasar berada dibawah ambang batasnya. Parameter laju kematian alami dirasa tidak mungkin untuk dikontrol, termasuk laju perpindahan pengguna yang positf HIV menjadi AIDS karena pada dasarnya hal ini pasti akan terjadi pada seseorang individu yang telah positif HIV. Empat parameter lainnya memperlihatkan bahwa rata-rata banyaknya kedatangan pengguna ke sebuah grup $(\lambda)$ memegang peranan besar. Secara trivial dapat dikatakan jika semakin sedikit jumlah individu yang datang dan menggunakan narkoba secara bersama-sama pada sebuah grup pengguna narkoba maka semakin sedikit penyebaran HIV dari seorang pengguna ke pengguna lain.

Data statistik memperlihatkan bahwa jumlah kasus HIV terus meningkat dari tahun ke tahun, termasuk yang diakibatkan oleh penggunaan narkoba secara bersama-sama dalam sebuah grup sehingga diperlukan strategi selain mengandalkan mengurangi jumlah kedatangan pengguna ke sebuah grup. Walaupun peluang seorang susceptible "membilas" alat suntik dan peluang seorang pengguna susceptible terpapar terinfeksi masih mungkin untuk dikontrol namun sulit untuk dilakukan. Selain dengan memperkecil rata-rata angka kedatangan, angka reproduksi dasar cukup signifikan dipengaruhi oleh jumlah banyaknya grup yang terbentuk. Ini diperlihatkan oleh simulasi yang ditampilkan oleh grafik berikut.
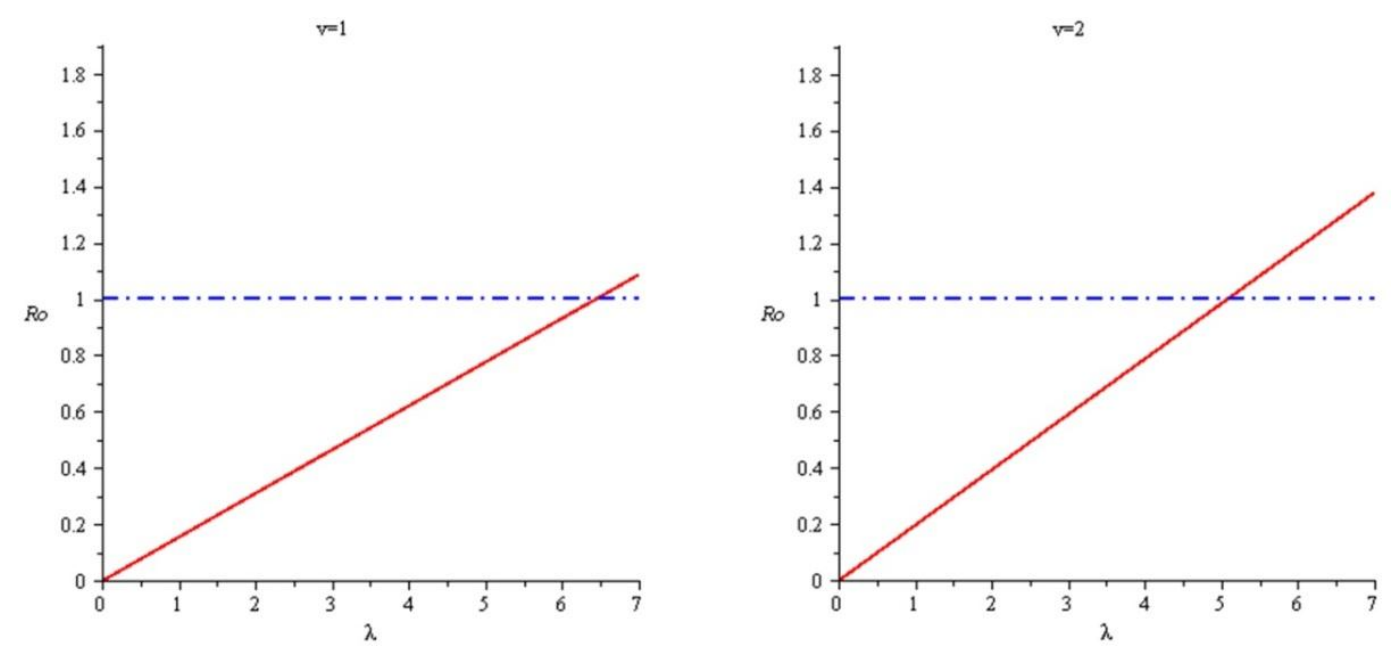

Gambar 3. Pengaruh laju kedatangan terhadap Ro

Gambar 4 memperlihatkan bahwa tingkat kedatangan sangat mempengaruhi angka reproduksi dasar secara signifikan 

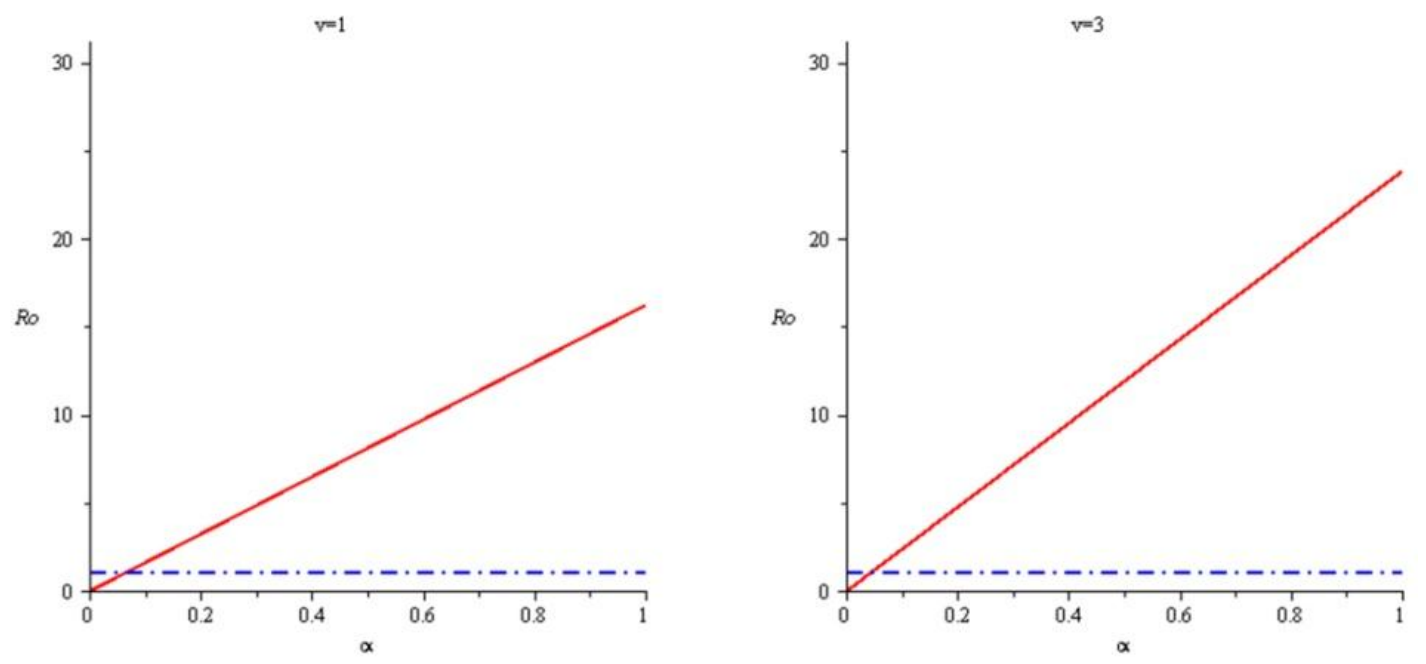

Gambar 4. Pengaruh a terhadap Ro
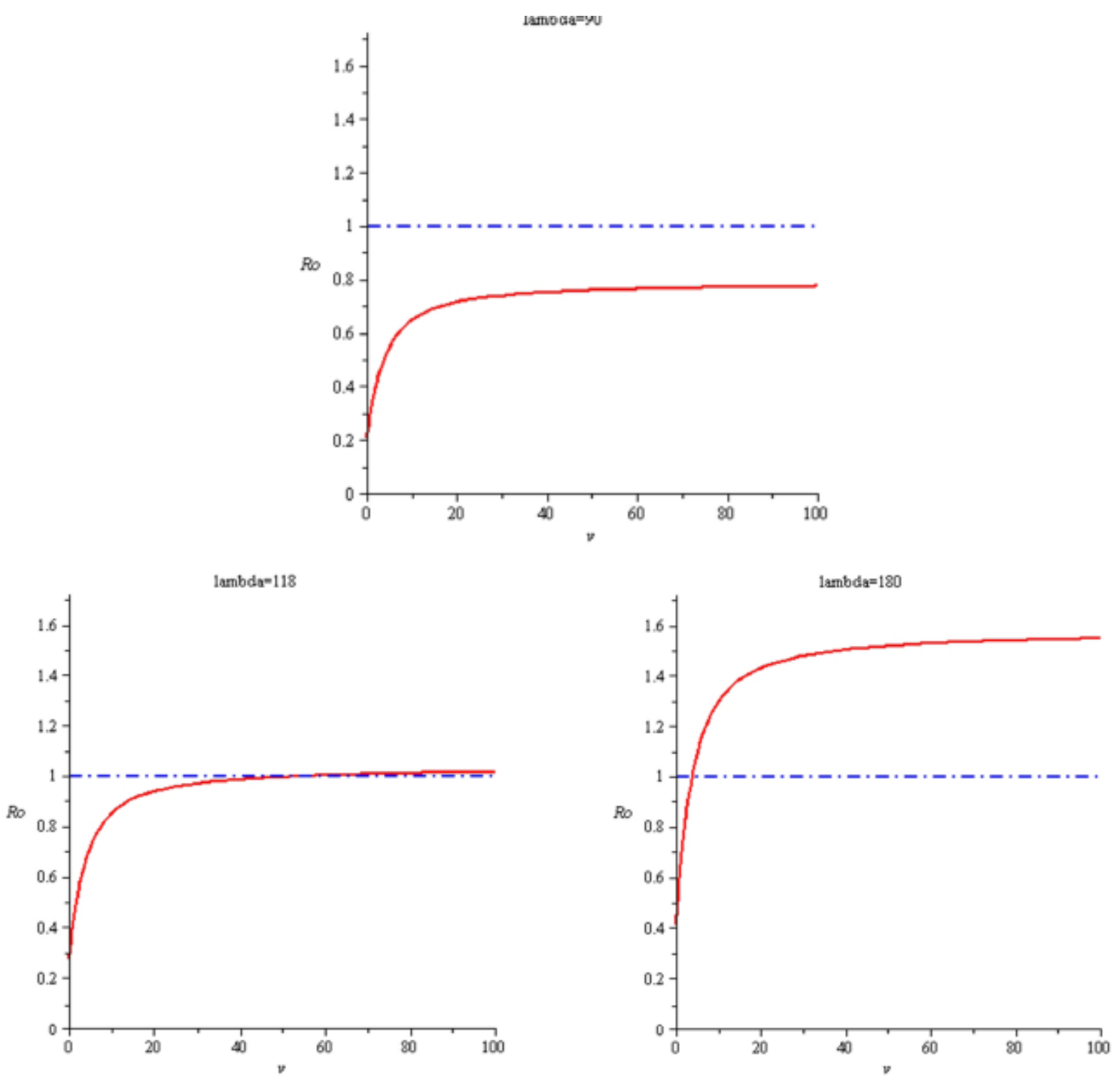

Gambar 5. Pengaruh jumlah grup terhadap Ro 
Gambar 4 memperlihatkan bahwa jika populasi hanya dibagi menjadi beberapa grup saja, maka angka reproduksi dasar meningkat tajam, tetapi jika dibagi dalam jumlah yang cukup banyak angka reproduksi dasar tidak naik dengan drastis walaupun jumlah kedatangan pengguna narkoba cukup besar. Hal ini dapat dilihat pada Gambar 5, dengan tingkat kedatangan $\lambda=118$ dan $\lambda=180$ (orang/satuan waktu) angka reproduksi dasar naik secara perlahan.

\section{Simpulan}

Penelitian memberikan beberapa poin yang bisa digunakan dalam rangka mencegah penyebaran HIV pada pengguna narkoba dengan cepat. Penyebaran HIV pada pengguna narkoba adalah hal yang kompleks karena masing-masing seperti menjadi mata rantai yang saling berkaitan. Berhenti menggunakan narkoba sehingga tidak ada kedatangan pada grupgrup pengguna narkoba adalah langkah paling berpengaruh dalam mencegah penyebaran HIV. Hal ini juga sudah dibuktikan secara trivial oleh angka reproduksi dasar. Namun angka reproduksi dasar juga dapat ditekan agar tidak naik secara drastis walaupun tingkat kedatangan pada grup cukup tinggi adalah dengan membagi populasi pengguna narkoba pada grup yang banyak. Semakin banyak grup maka semakin menghambat kenaikan angka reproduksi dasar.

\section{Daftar Pustaka}

[1] Atkinson, J., 1996. A Simulation Model of the Dynamics of HIV Transmission in Intravenous Drug Users. Computers and Biomedical Research 29, 338-349.

[2] Ditjen PP \& PL Kemenkes RI. 2010-2013. Data Statistik Kasus HIV/AIDS di Indonesia.

[3] Jorgensen, S.E. 1983. Application of Ecological Modelling in Environment Management, part A. Elsevier Sci.

[4] Van Dyne, G.M. 1969. The Ecosystem Concept in Natural Resource Management. Academic Press, New York.

[5] Bacaer, N., Abdurahman, \& X., Ye, J., 2006. Modelling the HIV/AIDS Epidemic Among Injecting Drug Users and Sex Workers in Kunming, China. Bulletin of Mathematical Biology 68, 525-550.

[6] Capasso, V., Morale, D. 2001. Mathematical Models for HIV transmission among Injecting Drugs Users. Journal Of Biological Systems, volume 3. 747-758.

[7] Castillo-Chavez, C., Cooke, K., Huang, W., \& Levin S. A., 1989. On the Role of Long Incubation Periods in the Dynamics of Acquired Immunode.ciency Syndrome (AIDS). Part 1: Single Population Models. J Math Biol 27, 373-398.

[8] Greenhalgh, D., \& Hay, G., 1995. Mathematical Modelling of the Spread of HIV/AIDS amongst Injecting Drug Users. IMA Journal of Mathematical Applied in Medicine and Biology 14, 11-38.

[9] Diekman O. Heesterbeek JAP. (2000). Mathematical Epidemiology of Infection Diseases: Model Building, Analysis and Interpretation. John Wiley \& Sons, Chicchester. 